\title{
ATUALIZAÇÃO DAS FIGURAS DA SUBJETIVIDADE REVOLUCIONÁRIA: Proletariado
} versus Multidão

\author{
Flávio Bezerra de Farias
}

Universidade Federal do Maranhão (UFMA)

Juliana Carvalho Miranda Teixeira

Université Paris 8 / Universidade Federal do Maranhão (UFMA)

ATUALIZAÇÃO DAS FIGURAS DA SUBJETIVIDADE REVOLUCIONÁRIA: Proletariado versus Multidão

Resumo: O artigo examina a noção de subjetividade revolucionária em autores diversos e em situações históricas distintas. Situa a pós-modernidade para a discussão em torno da ideia de que o marxismo e o negrismo partem de certa herança teórica de Spinoza para representar figuras da subjetividade revolucionária. Do marxismo, apresenta o proletariado como uma totalidade concreta; e, no segundo caso, a multidão como uma totalidade abstrata.

Palavras-chave: Subjetividade revolucionária, pós-modernidade, proletariado, multidão.

UPDATE OF FIGURES OF REVOLUTIONARY SUBJECTIVITY: Proletariat versus Multitude

Abstract: The article examines the notion of revolutionary subjectivity in different authors and in different historical situations. Locates the postmodernity to the discussion around the idea that Marxism and negrism depart from certain theoretical heritage of Spinoza to represent figures of revolutionary subjectivity.From Marxism, presents the proletariat as a concrete totality; and, in the second case, the crowd as a whole abstract.

Keywords: Revolutionary subjectivity, postmodernity, proletariat, multitude. 


\section{INTRODUÇÃO}

A discussão teórica em torno da "figura categorial" que se engaja no processo da transformação social com vistas à emancipação humana não findou com a modernidade. O movimento da era pós-moderna ressignificou esse debate e apresentou novas formas, novas "figurações processuais", potencialmente subversivas diante da dinâmica mesmo de uma sociedade já em crise.

Contudo, somente uma práxis consciente poderia explicitar a experiência real que o mundo faz consigo mesmo no quadro situado para além do fordismo e na era da globalização. No decorrer desta grande transformação social e histórica, importa fazer um balanço analítico crítico dos movimentos altermundialistas para elaborar antecipações concretas que contribuam para as lutas reais contra as diversas manifestações das opressões classistas (dominação, exploração e humilhação).

Componentes de movimentos assumidamente altermundialistas estão estimulados a participar de um debate em torno da subjetividade revolucionária (sejam as tendências e as latências, sejam o proletariado marxista e a multidão negrista) no momento em que se vê ampliada e aprofundada mais uma crise do capitalismo global.

\section{DETERMINAÇÃO DA SUBJETIVIDADE REVOLUCIONÁRIA}

Para além dos tempos líquidos (BAUMAN, 2007) e das antinomias pós-modernas (JAMESON, 1997), com a crise global do capitalismo do início do século $X X I$, a subjetividade revolucionária deve se atualizar sob uma forma capaz de ser apreendida, com referências, delimitações, dimensões e apoios que lhe permitam uma consciente retomada de fôlego e vigor na dinâmica das lutas emancipatórias.

A subjetividade revolucionária escapa da fluidez e da polaridade reificadas para se tornar uma figuração processual que, em vez de se opor ao fluxo dinâmico, "[...]é o signo de que este fluxo desemboca sobre alguma coisa: sobre algo progressivamente determinado[...]" - pois, tanto as figuras, quanto o seu conceito

"[...] continuam a se modificar em formas sempre novas pela simples razão de que são ainda muito pouco determinadas. Sua determinação não se bloqueia de maneira alguma, mas as revela exatamente superando-as, abrindo-as para o futuro delas mesmas." (BLOCH, 1981, p. 143-144).

Sobre oque será determinado, Spinoza avançou um princípio dialético decisivo seja em abordagens marxistas (MARX, 1976, p. 671), seja em abordagens estruturalistas (NEGRI, 1982, p. 135; NEGRI, 2010, p. 9 et seq.) da subjetividade revolucionária, a saber, omnis determinatio est negatio. Vale ressaltar que a ontologia spinozista é profundamente marcada pela ideia da multiplicidade. O indivíduo é uma composição de múltiplos elementos. Desta forma, as multiplicidades, os distintos indivíduos estão aptos a estabelecer o sujeito político, já que o múltiplo está na origem de todas as coisas. Cada coisa é composta de uma multiplicidade determinada e participa de tantas outras formas múltiplas de organização (TEIXEIRA, 2011). Para Spinoza,

No que concerne ao problema da figura, digo que não é algo positivo, mas uma negação. É manifesto que a matéria em sua integridade não pode ter figura e deve ser considerada indefinida, a figura só existindo nos corpos finitos ou determinados. Com efeito, quem diz que percebe uma figura indica somente que concebe uma coisa determinada e de que maneira ela o é. Esta determinação, portanto, não pertence ao ser da coisa, mas indica o seu não ser. Portanto, a figura é apenas a determinação e a determinação é negação e, assim, ela não pode ser algo, mas só uma negação. (SPINOZA, 2007, p. 283-284).

Quanto a isto, tem-se que "[...] a forma (o modo de ser da singularidade) pode ser concebida como negação [...]", e a negação aqui entendida "[...] como momento de determinação da figura de toda coisa finita exprime a relação de todo ser singular ao ser-outro dos outros seres [...]" (LUKÁCS, 2009, p. 168-169).

Assim, a dialética marxiana parte desta ideia spinoziana para mostrar que os proletários não se unificam, a priori, como força de trabalho da população ativa, mas que também se diversificam como membros de uma imensa superpopulação relativa, tornando-se figura da ordem objetiva, relacionada com o processo de acumulação do capital historicamente determinado, conforme será mostrado a seguir.

2.1 Proletariado: a subjetividade revolucionária marxista

A elaboração da subjetividade revolucionária própria à abordagem marxista teve como ponto de partida efetivo a ideia de população, "representação caótica", abstração que se obtém quando se despreza as "classes que a compõem". Como decorrência mesmo da aplicação do método da economia política, dos "conceitos cada vez mais simples" restituiu a população "[...] com uma rica totalidade de determinações e relações diversas [...]" (MARX, 1982, p. 14).

As abstrações procedidas por Marx teve como fundamento, tal como salientado anteriormente, o princípio dialético spinozista determinar é negar, perceptível no concreto pensado da figura do 
proletariado enquanto unidade que revela as diversas condições do ser social no seio de uma configuração socioeconômica particular. Na busca das figuras da ordem objetiva, as categorias "[...]não se contentam, então, de reproduzir, de refletir, mas, elas próprias, fazem evoluir suas formas de maneira objetiva." (BLOCH, 1981, p. 154).

O ser, segundo as elaborações de Marx (1982), distingue-se em três grandes tipos, a saber, a natureza inorgânica, a natureza orgânica e a sociedade, conforme a figura a seguir:

Figura 1 - Figuração processual marxista da formação socioeconômica

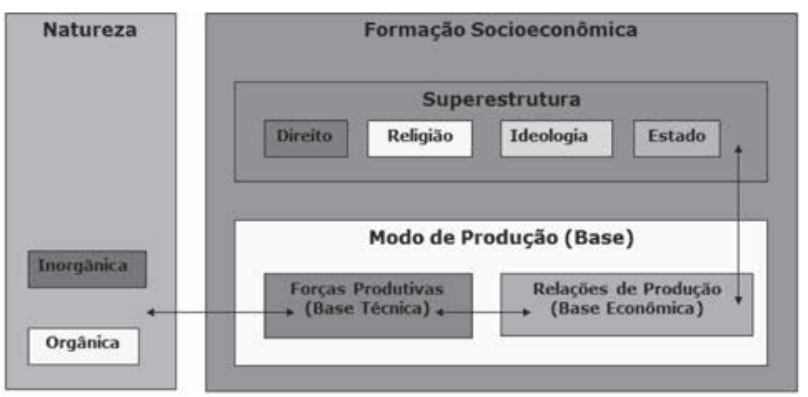

Fonte: Marx, (1982), Farias, (1988).

Lukács (2009, p. 39) sublinhou que a coexistência destes três grandes tipos de ser, com suas interações e diferenças essenciais, torna-se uma referência

"[...] tão imutável de todo ser que nenhum conhecimento do mundo que se desdobre neste terreno, nenhum conhecimento de si do homem seriam possíveis se não se reconhecesse como primordial um fundamento tão variado."

Servindo de base para uma práxis consciente.

Neste contexto, a particularização dos seres da natureza orgânica e inorgânica determina o seu outro, a saber: o ser social como forma de existência distinta, que se totaliza contraditória e concretamente numa formação socioeconômica. Nesta, a dinâmica da base econômica - que encerra a contradição fundamental entre produção coletiva e apropriação privada é o quadro no qual atua a lei geral da acumulação capitalista, que rege a figuração processual do conjunto e dos subconjuntos da força de trabalho ativa e da superpopulação relativa (MARX, 1976).

Figura 2 - Proletariado em Marx

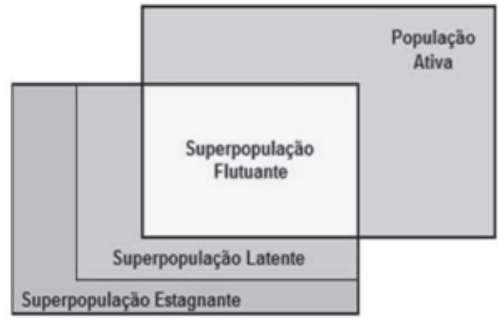

Fonte: MARX (1982)
Os subconjuntos da força de trabalho são historicamente determinados e figurados como o múltiplo de um mesmo (BLOCH, 1981), em que o específico está numericamente determinado por subconjuntos que o unificam e, deste modo, o resumem; o conjunto da força de trabalho aparece no tempo e no espaço, encerrando a multiplicidade e tolerando no seu quadro as diferenças (ibidem). Trata-se de

[...] arquétipos que se reproduzem aparentemente sem mudança, mas não permanecem de maneira alguma prisioneiros do passado [...] É precisamente o fato que se possa falar deles como de um gênero que permite apreender a passagem dos arquétipos às categorias autênticas deste gênero, ou mais precisamente sua revelação nelas - um desvendar incontestavelmente carregado de um conteúdo que não tem nada de comum com conceitos gerais puramente formalistas. (Ibidem, p. 152, tradução nossa).

Por outro lado, considera-se que a dominação estatal do homem pelo homem na era da globalização poderia ser expressa na figura seguinte:

Figura 3 - O modo estatal capitalista global e o imperialismo global

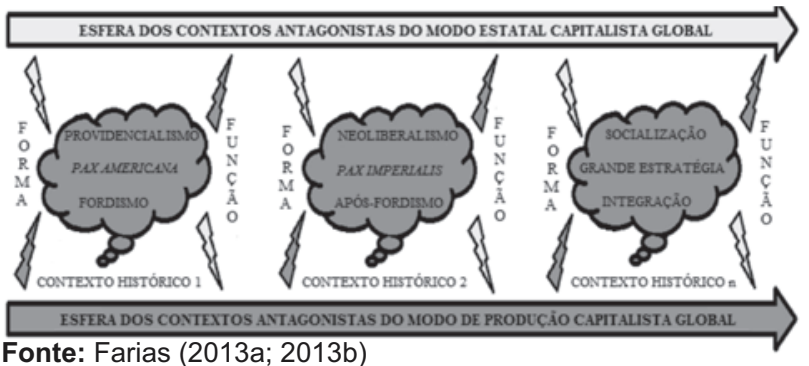

$\mathrm{Na}$ esfera destes contextos historicamente determinados, considera-se, da mesma forma, que tanto a exploração quanto a humilhação do homem pelo homem para além do quadro de dominação ilustrado, determinam a unidade e a diversidade do proletariado, condição atualizada conforme o expresso na figura abaixo.

Figura 4 - Unidade e diversidade do proletariado

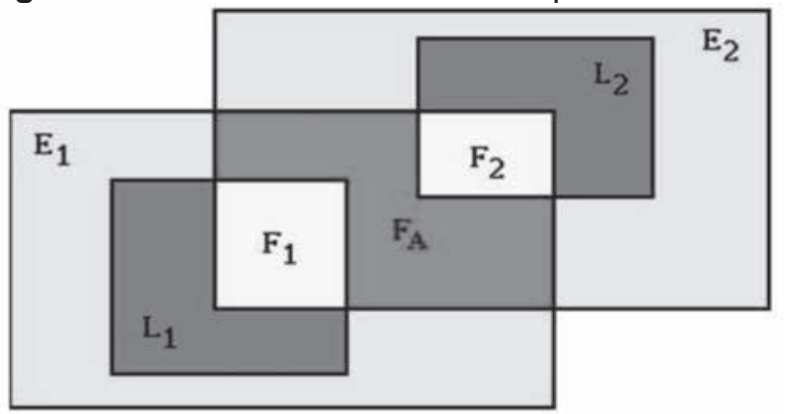

Fonte: Farias (2013a; 2013b) 


\begin{tabular}{|c|l|l|l|c|}
\hline \multirow{2}{*}{ Legenda } & Assalariados & \multicolumn{3}{|c|}{ Superpopulação relativa } \\
\cline { 2 - 5 } & $\mathrm{F}_{1}+\mathrm{F}_{2}+\mathrm{F}_{\mathrm{A}}$ & Flutuante $=\mathrm{F}_{1}+\mathrm{F}_{2}$ & Latente $=\mathrm{L}_{1}+\mathrm{L}_{2}$ & $\begin{array}{c}\text { Estagnante }=\mathrm{E}_{1} \\
+\mathrm{E}_{2}\end{array}$ \\
\hline
\end{tabular}

Fontes: Marx (1976); Farias (1988).

Nessa figuração processual, as diversas condições do proletariado foram determinadas por intermédio da negação, referenciada no núcleo em que se encontra a força de trabalho ativa. $O$ proletariado exprime-se em conjunto e subconjuntos da força de trabalho, cujas condições de unidade e diversidade dependem da dinâmica da acumulação do capital. As cores representam as particularidades das condições de flutuante, latente e estagnante. Enquanto que os índices 1 e 2 apontam para determinadas especificidades, polarizadas em termos de diferenças quanto ao sexo, a idade, a raça dentre outras variáveis que expressam a condição própria da superpopulação discriminada relativamente ao proletariado ativo.

Assim, a superpopulação na forma flutuante corresponde hoje à condição dos assalariados que se ajustam aos contratos com duração determinada ou provisórios, sem estabilidade. A superpopulação latente constitui a imensa parte do exército de reserva, imediatamente atraída pelo capital desde que seja necessário. Corresponde hoje à fração de desempregados à espera de trabalho e imediatamente empregáveis. A terceira categoria da superpopulação relativa, a estagnante, se situa às margens externas do exército de reserva, e é composta de trabalhadores que possuem poucas chances de serem recrutados pelo capital (seja pela idade, qualificação entre outros fatores limitantes). Quando empregados, são os mais desqualificados e mal pagos. A análise concreta desta figuração processual situada no tempo e no espaço evidencia que, na grande transformação social e histórica atual, a opressão classista se amplia, mas com mudança qualitativa, assumindo novas formas.

As figuras referenciadas na abordagem crítica e revolucionária marxiana

[...] não poderiam ser pensadas e só são, além do mais, possíveis realmente no quadro de um processo que as transforme, as empurre mais longe e que é ele próprio utópico e aberto. (BLOCH, 1981, p. 164).

$\mathrm{Na}$ superação do capitalismo global por intermédio do socialismo, no contexto da utopia concreta do comunismo, "[...] figuras processuais dialéticas se evadem delas próprias, pertencem ao processo como figuras de tensão, figuras de tendências." (BLOCH, 1981, p. 158).
2.2 A Multidão: subjetividade revolucionária negrista

A tentativa de atualização mais recente da subjetividade revolucionária, bem como do momento histórico atual, foi feita por Negri em parceria com Michael Hardt (2000; 2004). Mas já no início dos anos 1980, Negri (1982) esboçou as primeiras linhas da teoria em torno da "[...] figura do sujeito político da constituição democrática. Pós-moderna - a multidão - de inspiração também spinoziana, superando assim, e em parte, o apego teórico à figura do operário-massa, ora saudada pelo operaísmo italiano logo após os acontecimentos de 1968.

Ao proclamar a pós-modernidade de bemaventurança, Negri e os seus adeptos desprezaram, como os demais pós-modernos, a premissa da sociedade dividida em classes e a luta de classes foi reduzida ao esquema dicotômico-antinômico da multidão versus o Império pós-moderno.

A multidão de singularidades ora subsumida pelo Império manifesta duas maneiras de sermultidão (NEGRI, 2010, p. 111 et seq.). A primeira é o próprio ser-multidão e refere-se à relação entre as singularidades que a constituem; a segunda é caracterizada pelo fazer-multidão, "[...] processo material e coletivo dirigido pela paixão comum [...]" (NEGRI, 2010, p. 112). Em outros termos, é o movimento da multidão contra quando ela é "[...] aprisionada e transformada no corpo do capital global, ela é tomada no processo de globalização capitalista e se opõe." (HARDT; NEGRI, 2004, p. 127), enquanto multidão a favor do reino do comum (HARDT; NEGRI, 2004, p. 99).

Ainda, neste mesmo movimento teríamos antagonicamente, "[...] sem mediação de qualquer tipo" (HARDT; NEGRI, 2000, p. 474) os dois referidos polos, Império e multidão, com configurações que se diferenciam à medida que a multidão - alternativa vivaz que cresce no seio do Império - descobre "[...] o comum que the permite comunicar e agir em conjunto [...]" pela "[...] transformação do mundo [...]" (HARDT; NEGRI, 2004, p. 7; 401). Destacase que para os negristas essa relação não sofre as interferências da dialética cujo poder "[...] foi definitivamente anulado [...]" (HARDT; NEGRI, 2000, p. 487).

$\mathrm{Na}$ era da mundialização, o Império pósmoderno "[...] estende em escala planetária sua rede 
de hierarquias e de divisões, cuja função é de manter a ordem através de novos mecanismos de controle e de conflito incessante [...]" (HARDT, NEGRI, 2004, p. 7), subsumindo a multidão de pobres empregados em trabalhos materiais e imateriais e desempregados a esse processo, bem como ao modelo "republicano" de democracia.

Antagonicamente e ao mesmo tempo, compreendido que essa relação "[...] é um contraste que não acaba de se produzir, um conflito que se dá continuamente." (NEGRI, 2010, p. 43), esta multidão multicolorida de pobres (que constitui a própria imagem invertida desse Império) já resiste com a proposição altermundialista "[...] de criar uma sociedade alternativa" (HARDT; NEGRI, 2004, p. 351), à "[...] subsunção real da sociedade [...]", do "[...]c omunismo do capital [...]" (NEGRI, 2010, p. 36 ; 76) em nome do projeto do comum, de "[...] desenvolvimento de uma verdadeira democracia revolucionária das lutas [...]" pela força subversiva do amor e da imaginação (NEGRI, 2010, p. 25; 78). Deste modo, a ideia de multidão negrista cai num relativismo histórico destruidor, o qual precisamente é

"[...] excluído pelo excedente presente nas categorias, um excedente que provém em parte de arquétipos eles próprios ricos em excedentes e que impedem as categorias de murcharem num sistema frágil, desencarnado e esquelético, digno de um pensamento rígido por falta de imaginação." (BLOCH, 1981, p. 154).

Das inúmeras metáforas lançadas pelos negristas para tentar explicar a estrutura contemporânea do biopoder e da resistência dos pobres, concebe-se o esquema figurável abaixo que reifica tanto a dinâmica contemporânea do capitalismo em crise, quanto a condição da subjetividade revolucionária. Trata-se de uma concepção estruturalista de uma figuração abstrata que veicula sem dúvida vestígios de conteúdo, mas somente por meio do recurso a elementos típicos de uma antinomia que traz a marca do choque de civilizações.

Deste modo, as figuras do Império e da Multidão tornaram-se o arquétipo da subjetividade revolucionária pós-moderna, conforme a Figura 4, abaixo. Esta abordagem estruturalista

[...] permanece, quanto a ela, incontestavelmente prisioneira de um recurso arcaizante, em razão de sua insistência sobre a permanência de uma forma de presença que fica voltada para o passado. (BLOCH, 1981, p. 152).

Além disso, e

[...] do mesmo modo que os arquétipos não têm a sua sorte ligada ao destino do arcaico, as categorias não são mais do que eles ligadas à época de seu nascimento e de sua validade, isto é, redutíveis a períodos de maneira tal que cada uma dessas épocas teria sua própria doutrina das categorias. Ao contrário, percebe-se justamente sua validade persistir e avançar na história, trazendo-lhe seu concurso e seu testemunho [...] (BLOCH, 1981, p. 153).

Figura 5 - Figuração especulativa negrista da subjetividade revolucionária

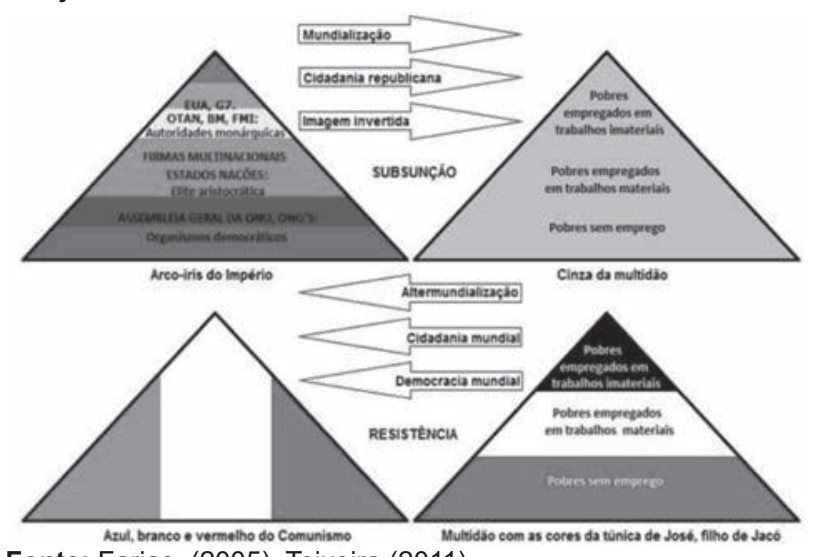

Fonte: Farias, (2005), Teixeira (2011).

Embora traga elementos novos, este arquétipo pós-moderno vem de uma utilização passadista de estruturas arcaicas que se perpetuam inalteravelmente "[...] em tipos originários persistentes que a história se contenta de travestir [...]" (BLOCH, 1981, p. 151).

\section{CONCLUSÃO}

$\mathrm{Na}$ era pós-moderna, os movimentos altermundialistas veem-se diante da necessidade de uma atualização da categoria da subjetividade revolucionária. Como visto acima, para o altermundialismo marxista, a atualização dialética da subjetividade revolucionária passa por figurações processuais que vão para além desta democracia como arquétipo universal, num processo de democratização socialista,

[...] representando heranças [que] não permanecem vinculadas ao primeiro momento de sua formulação, a um contexto que era quase sempre mítico. Em vez disso, atravessam a história vendo constantemente mudar sua função e podem até mesmo experimentar aí um novo nascimento [...] (BLOCH, 1981, p. 152).

Para o altermundialismo pós-marxista, estáse indubitavelmente diante da práxis revolucionária da multidão que, na era do Império, resiste pela 
antecipação de um comunismo, paradoxalmente fixado como figura imóvel no quadro passadista da democracia burguesa formal.

\section{REFERÊNCIAS}

BAUMAN, Zygmunt. Tempos líquidos. Rio de Janeiro: Jorge Zahar Ed., 2007.

BLOCH, Ernst. Experimentum Mundi. Paris: Payot, 1981.

FARIAS, Flávio Bezerra de. L'État et le processus de socialisation capitaliste au Brésil. 1988. Tese (Doutorado de Estado) - Universidade Paris-Nord (Paris XIII), Villetaneuse, 1988.

$\overline{2013 a}$

O modo estatal global. São Paulo: Xamã, $\overline{2013 b}$

O imperialismo global. São Paulo: Cortez,

HARDT, Michael; NEGRI, Antonio. Empire. Paris: Exils Éditeur, 2000.

Multitude: guerre et démocratie à l'âge de l’Empire. Paris: La Découverte, 2004.

JAMESON, Fredric. As sementes do tempo. São Paulo: Ática, 1997.

LUKÁCS, Georges. Prolégomènes à l'ontologie de l'être social. Paris: Éditions Delga, 2009.

MARX, Karl. Le capital. Paris: Éditions Sociales, 1976. 3 v.

Para a crítica da economia política. São Paulo: Abril Cultural, 1982.

NEGRI, Antonio. Spinoza et nous. Paris: Galilée, 2010.

L'anomalie sauvage. Paris: PUF, 1982.

SPINOZA, Baruch de. Traité politique / Lettres. Paris: GF Flammarion, 2007.

TEIXEIRA, Juliana Carvalho Miranda. La genèse et la puissance de la multitude: pour la critique de l'altermondialisme chez Negri. 2011. Dissertação (Mestrado em Ciências Sociais) - Universidade Paris X, Nanterre, 2011.

\section{Flávio Bezerra de Farias}

Economista

Doutorado de Terceiro Ciclo em Economia e Gestão pela Universidade de Amiens, Doutorado de Estado em Economia pela Universidade Paris-Nord.
Professor do Departamento de Economia e do Programa de Pós-Graduação em Políticas Públicas da UFMA

E-mail: flaviobezerradefarias@gmail.com

\section{Juliana Carvalho Miranda Teixeira}

Assistente Social

Doutoranda da Université Paris 8 / Universidade Federal do Maranhão (UFMA)

E-mail: juliana.cmt@gmail.com

Universidade Federal do Maranhão (UFMA)

Avenida dos Portugueses, 1 - Bacanga, MA, CEP: 65085-580, São Luís - MA, Brasil.

\section{Université Paris 8}

2 Rue de la Liberté, 93200 Saint-Denis, França 